\title{
Literature Review : Tentang Massage Effleurage Terhadap Respon Nyeri Pada Ibu Bersalin Kala I
}

\author{
Fatturichza Yamiendinar ${ }^{1 *}$, Isyti'aroh ${ }^{2}$, Windha Widyastuti ${ }^{3}$ \\ ${ }^{1,2,3}$ Program Studi Diploma Tiga Keperawatan, Universitas Muhammadiyah Pekajangan \\ Pekalongan, Indonesia \\ *email:fatturichzadinar@gmail.com
}

\begin{abstract}
Contraction during labour can be painful. The pain due to labour process can be reduced by performing non-pharmacological treatment of Effleurage. Effelurage is a serries of massage which is done in the abdominal area aiming to reduce pain that arises during the labour process. The purpose of this study was to find out whether Effleurage could reduce pain response of mothers in the first phase labour. The study was a literature review of three articles taken from Google Scholar with the keyword "Effleurage", "labour pain" and "first phase" in the form of fulltext articles, published in 2019. The respondents of the thre articles 63 mothers who gave birth. The average value of pain response showed by the respondents before and after being treated with Effleurage decreased from 5.883 to 3.576. Therefore, it was concluded that effleurage could be given to mothers to reduce the pain response in the labour process. Moreover, health providers are expected to treat mothers with Effleurage to reduce their pain to the labour process.
\end{abstract}

Keywords: First phase, labour pain, Massage effleurage

\begin{abstract}
Abstrak
Kontraksi selama persalinan dapat menimbulkan rasa nyeri. Rasa nyeri yang dirasakan pada proses persalinan tersebut dapat dikurangi dengan melakukan tindakan non-farmakologis salah satunya berupa pemberianmassage effleurage. Massage effleurage yang dilakukan di area perut untuk membantu mengurangi rasa nyeri yang muncul pada proses persalinan. Tujuan karya tulis ilmiah ini untuk mengetahui apakah massage effleurage dapat menurunkan respon nyeri pada ibu bersalin kala I berdasarkan literatur review. Desain karya tulis ilmiah berupa literatur review dengan jumlah artikel tiga yang diambil dari laman jurnal google scholar dengan kata kunci "massage effleurage". "nyeri persalinan" dan "kala I" berupa artikel fulltext, terbit tahun 2019. Jumlah responden dari tiga artikel tersebut adalah 63 ibu bersalin. Nilai rata-rata respon nyeri sebelum dilakukan massage effleurage 5,883, dan nilai rata-rata respon nyeri setelah dilakukan massage effleurage 3,576. Simpulannya adalah tindakan massage effleurage dapat membantu menurunkan respon nyeri pada proses persalinan. Saran bagi pelayanan kesehatan agar dapat menerapkan teknik massage effleurage untuk mengurangi nyeri pada proses persalinan.
\end{abstract}

Kata kunci: Massage effleurage,nyeri persalinan, kala I

\section{Pendahuluan}

Persalinan merupakan suatu proses pengeluaran janin atau hasil konsepsi dari dalam kandungan atau kehidupan dalam rahim yang cukup bulan, yang ditandai dengan keluarnya lendir bercampur darah melalui serviks yang telah membuka, dan disusul dengan lahirnya plasenta [10]. Nyeri persalinan mulai timbul pada persalinan kala I yang berasal dari kontraksi uterus dan dilatasi serviks. Makin bertambahnya frekuensi kontraksi uterus, maka nyeri yang dirasakan akan bertambah semakin kuat. Kala I merupakan kala dilatasi dan penipisan serviks, terjadi karena adanya kontraksi uterus dan disebabkan adanya pergeseran ketika serviks mendatar. Kala I dapat ditandai dengan adanya pembukaan serviks sampai pembukaan lengkap $10 \mathrm{~cm}$ [1]. 


\section{Prosiding Seminar Nasional Kesehatan 2021 Lembaga Penelitian dan Pengabdian Masyarakat Universitas Muhammadiyah Pekajangan Pekalongan}

Nyeri pada proses persalinan merupakan pengalaman yang terjadi pada tubuh karena terkait dengan adanya kontraksi uterus, dilatasi dan penipisan serviks, dan adanya penurunan janin selama persalinan [11].Fenomena rasa nyeri yang dirasakan ibu bersalin kala I fase aktif yaitu nyeri saat kontraksi, mules, dan akan merasakan seperti ingin BAB. Nyeri yang terjadi dapat mempengaruhi kondisi ibu seperti kelelahan, rasa takut, khawatir dan akan menimbulkan stres. Stres akan mengakibatkan kontraksi rahim tidak efektif dan dapat berakibat pada persalinan yang lama [10].

Berdasarkan hasil penelitian yang dilakukan Ebirim, Buowari dan Ghosh (2012) bahwa dari 300 ibu bersalin kala I fase aktif didapatkan responden yang mengatakan nyeri berat terdapat $32 \%$, responden yang mengatakan nyeri sedang terdapat $57 \%$, sedangkan responden yang mengatakan nyeri ringan sebanyak $11 \%$. Sebanyak $68,3 \%$ ibu menyatakan bahwa nyeri persalinan adalah nyeri berat, sedangkan dari $86 \%$ lebih ibu menginginkan jika nyeri tersebut dapat diatasi. Penelitian yang sama dilakukan di Inggris, ibu bersalin mengungkapkan jika 93,5\% ibu menjelaskan bahwa nyeri persalinan termasuk nyeri yang berat, sementara penelitian yang sama juga dilakukan di Firlandia terdapat $80 \%$ wanita mendeskripsikan nyeri sebagai nyeri yang hebat dan tidak dapat diatasi atau ditoleransi [8].

Nyeri persalinan perlu ditangani agar ibu merasakan kenyamanan, cara mengatasi nyeri persalinan ada 2 yaitu farmakologi dan non farmakologi. Pengobatan farmakologi dengan menggunakan analgetik. Obat-obatan analgetik memberikan pereda nyeri bagi ibu bersalin tetapi juga dapat mempengaruhi janin dan proses persalinan. Obat-obatan nyeri yang diberikan terlalu dini dapat memperlambat persalinan dan membuat depresi pernafasan pada janin dan bayi baru lahir. Sedangkan metode non farmakologis yaitu dengan teknik relaksasi dan teknik pernafasan dalam persalinan, yang bersifat murah, simpel, efektif, tanpa efek yang merugikan dan dapat meningkatkan kepuasan selama persalinan, karena ibu dapat mengontrol perasaannya dan kekuatannya [10]. Metode non-farmakologis yang dapat dilakukan salah satunya adalahmassage effleurage. Massage effleurage merupakan teknik pemijatan dengan usapan lembut, lambat dan panjang, dan tidak putus-putus, dilakukan dengan menggunakan ujung-ujung jari yang ditekan secara lembut dan ringan, dan saat melakukan pemijatan diusahakan ujung jari tidak lepas dari permukaan kulit [7].

Berdasarkan penelitian yang dilakukan oleh Handayani [3] tentang "Massage Effleurage Terhadap Tingkat Nyeri Kala I Fase Aktif" responden yang mengalami penurunan tingkat nyeri sejumlah $26(92,9 \%)$ responden, dan yang mengalami tingkat nyeri tetap sejumlah $2(7,1 \%)$ responden. Rata-rata sebelum dan sesudah dilakukan massage effleurage, yaitu sebelum dilakukan massage effleuragesebesar 5,9642, dan rata-rata tingkat nyeri sesudah dilakukan massage effleurage sebesar 3,6071. Pemberian massage effleurage terhadap ibu inpartum kala I fase aktif menunjukkan hasil adanya pengaruh secara signifikan terhadap nyeri yang dirasakan ibu inpartu kala I fase aktif.

Permasalahan diatas membuat penulis mengangkat topik "Massage Effleurage Terhadap Respon Nyeri Pada Ibu Bersalin Kala I"sebagai topik dalam karya tulis ilmiah 


\section{Prosiding Seminar Nasional Kesehatan 2021 Lembaga Penelitian dan Pengabdian Masyarakat Universitas Muhammadiyah Pekajangan Pekalongan}

ini berdasarkan literature review. Penulis berharap agar pembacamengetahui apakah massage effleurage dapat menurunkan respon nyeri pada ibu bersalin kala I.

\section{Metode}

Metode yang digunakan dalam penelitian ini adalah literatur review. yaitu sebuah sintesis dari studi literature yang bersifat sistemik, jelas, menyeluruh, dengan cara mengkompilasi, mengklasifikasi dan mengevaluasi melalui pengumpulan data-data yang sudah ada dengan mencari 5 jurnal melalui google scholar menggunakan kata kunci "massage efflurage" dan "nyeri persalinan"kemudian diseleksi sesuai dengan topik yang dibahas dan melihat jenis penelitiannya yang sama-sama menggunakan quasy experiment, dan instrument yang digunakan pada penelitian adalah Numerical Rating Scale (NRS) 0-10.

\section{Hasil dan Pembahasan}

\section{Hasil}

Dari ketiga artikel jurnal yang telah direview menunjukkan hasil nilai rata-rata pengaruh sebelum dan sesudah diberikan terapi massage effleurage adalah sebagai berikut:

Tabel 3.1 Distribusi rata-rata respon nyeri sebelum dan sesudah dilakukan massage

$$
\text { effleurage }(n=63)
$$

\begin{tabular}{cc}
\hline Variabel & Mean \\
Respon Nyeri & 5,883 \\
\hline Sebelum & 3,576 \\
Sesudah & \\
\hline
\end{tabular}

Berdasarkan tabel diatas nilai mean sebelum dilakukan massage effleurage adalah 5,883 termasuk kategori nyeri sedang, dan setelah dilakukan massage effleurage nilai mean turun menjadi 3,576 (nyeri sedang).

\section{Pembahasan}

Berdasarkan ketiga artikel menyebutkan bahwa ibu bersalin mengalami nyeri persalinan dengan skala 6-7 yaitu termasuk kedalam nyeri sedang dan nyeri berat, dan ibu bersalin mengalami nyeri pada bagian perut. Hasil analisis data dari ketiga artikel tersebut menunjukkan rata-rata respon nyeri persalinan kala I dapat berkurang dengan melakukan tindakan massage effleurage. Hal ini sesuai dengan pernyataan Maryunani (2010) bahwa Massage effleurage atau tindakan mengusap-usap abdomensecara perlahan, seirama dengan pernafasan saat kontraksi, dapat digunakan untuk mengalihkan pikiran ibu, supaya ibu tidak memusatkan perhatiannya pada nyeri saat kontraksi [2]. Massage effleurage diberikan kepada ibu bersalin karena bermanfaat untuk menurunkan nyeri pada proses persalinan, dan bisa memberikan efek relaksasi serta membuat ibu bersalin menjadi rileks.

Ketiga artikel penelitian ini memiliki persamaan yaitu menggunakan teknik nonfarmakologis untuk membantu menurunkan dan mengurangi nyeri pada ibu bersalin. Intervensi yang dilakukan untuk mengurangi nyeri pada ibu bersalin tersebut adalah terapi massage effleurage. Menurut Indriyani (2016) Effleurage merupakan salah satu metode non farmakologis untuk mengurangi nyeri selama persalinan, dimana nyeri itu 


\section{Prosiding Seminar Nasional Kesehatan $\mathbf{2 0 2 1}$ Lembaga Penelitian dan Pengabdian Masyarakat Universitas Muhammadiyah Pekajangan Pekalongan}

terjadi pada kala I fase laten (pembukaan 0-3 cm) dan fase aktif (pembukaan 4-7 $\mathrm{cm}$ ). Effleurage dapat dilakukan oleh ibu bersalin sendiri atau pendamping persalinan selama kontraksi berlangsung. Hal ini digunakan untuk mengalihkan perhatian ibu dari nyeri saat kontraksi [4]. Hal ini sesuai dengan pernyataan menurut Wulandari dan Hiba (2015) menjelaskan bahwa salah satu tindakan yang mampu memberikan efek relaksasi dan mampu menurunkan rasa nyeri adalah dengan melakukan massage effleurage [2].

Massage effleurage dapat mengurangi respon nyeri karena massage tersebut mempunyai efek distraksi dan juga relaksasi serta dapat meningkatkan pembentukan hormon endorphinesystem control dasenden. Endorphine merupakan hormon yang membuat ibu menjadi lebih nyaman [6]. Hormon endorphine ini dapat meningkatkan kenyamanan pada ibu bersalin. Tingkat kenyamanan ini akan mengurangi sensasi nyeri yang dirasakan oleh ibu.

Instrumen penelitian yang digunakan dalam ketiga artikel ini adalah dengan menggunakan lembar observasi Numerical Rating Scale (NRS). Instrumen yang digunakan tersebut terbukti mampu untuk membantu mengukur respon nyeri pada proses persalinan dari skala $0-10$, skala verbal yang membantu mengukur tingkatan nyeri dari intensitas tidak nyeri sampai dengan intensitas nyeri yang tidak dapat terkontrol lagi [5]. Penelitian ini dilakukan menggunakan lembar obeservasi, observasi yang dilakukan adalah dengan mencatat hasil intensitas nyeri menggunakan skala verbal yang telah digunakan pada ibu bersalin, berguna untuk mengetahui skala nyeri yang dirasakan ibu bersalin sebelum dan sesudah dilakukan intervensi.

Hasil dari ketiga penelitian tersebut dapat disimpulkan bahwa tindakan massage effleurage dapat membantu mengurangi respon nyeri pada saat proses persalinan secara signifikan. Hal ini didukung oleh penelitian Handayani tahun 2016 yang menunjukkan bahwa responden sebelum diberikan massage effleurage yaitu sebanyak 12 responden $(39,3 \%)$ nyeri berat, 15 responden $(53,6 \%)$ nyeri sedang, dan 2 responden $(17,1 \%)$ nyeri ringan, sedangkan sesudah diberikan massage effleurage yaitu sebanyak 2 responden $(7,1 \%)$ nyeri berat, 12 responden (42,9\%) nyeri sedang, dan 14 rsponden (50\%) nyeri sedang, sehingga menunjukkan bahwa massage effleurage efektif untuk membantu mengurangi respon nyeri pada proses persalinan.

\section{Kesimpulan}

Berdasarkan literature review yang dilakukan dapat disimpulkan bahwa tindakan massage effleurage dapat membantu mengurangi respon nyeri pada pasien bersalin, pengukuran intensitas nyeri dilakukan dengan menggunakan lembar observasi Numerical Rating Scale (NRS). Berdasarkan dari 3 artikel tersebut ditemukan nilai mean sebelum dilakukan massage effleurage adalah 5,883 termasuk kategori nyeri sedang, dan setelah dilakukan massage effleurage nilaimean turun menjadi 3,576 (nyeri sedang).

\section{Referensi}

[1] Aspiani, R.Y. (2017). Buku Ajar Asuhan Keperawatan Maternitas Aplikasi Nanda, NIC dan NOC. Jakarta: TIM, 2017. 


\section{Prosiding Seminar Nasional Kesehatan 2021 Lembaga Penelitian dan Pengabdian Masyarakat Universitas Muhammadiyah Pekajangan Pekalongan}

[2] Ersila, W., Prafitri, L.D., \& Zuhana, N. (2019). Perbedaan efektivitas massage effleurage dan kompres dingin terhadap nyeri persalinan di puskesmas kabupaten Pekalongan. Jurnal SIKLUS, 8(2), 107-115. https://doi.org/10.30591/siklus.v8i2.1146.

[3] Handayani, S. (2016). Massage effleurage terhadap tingkat nyeri kala I fase aktif. Jurnal Kesehatan "Samodra IImu", 7(2), 122-132. https://stiksyogyakarta.e-journal.id/JKSI/article/view/27.

[4] Herinawati., Hindriati, T., \& Novilda, A. (2019). Pengaruh effleurage massage terhadap nyeri persalinan kala I fase aktif di praktik mandiri bidan Nuriman Rafida dan praktik mandiri bidan Latifah kota Jambi tahun 2019. Jurnal IImiah Universitas Batanghari Jambi, 19(3), 590-601. https://doi.org/ 10.33087/jiubj.v19i3.764.

[5] Judha, M., Sudarti., \&Fauziah, A. (2014). Teori Pengukuran Nyeri \& Nyeri Persalinan. Yogyakrta: Nuha Medika.

[6] Maslikhanah. (2011). Penerapan teknik pijat effleurage sebagai upaya penurunan nyeri persalinan pada ibu inpartu kala I fase aktif di Polindes Kembangringgit Kec. Pungging Kab. Mojokerto. (Tesis Universitas Sebelas Maret Surakarta). https://digilib.uns.ac.id/

[7] Padila. (2017). Keperawatan Maternitas. Yogyakarta: Nuha Medika.

[8] Pratiwi, I.G., \& Diarti, M.W. (2019). Studi literatur: Metode non farmakologi mengurangi nyeri persalinan dengan menggunakan effleurage massage. Jurnal Kesehatan Poltekkes Ternate, 12(1), 141-145. https://doi.org/ 10.32763/juke.v12i1.108.

[9] Ratnawati, A. (2017). Asuhan Keperawatan Maternitas. Yogyakarta: Pustaka Baru Press.

[10] Rika, V.N.A., \& Aryanti, L. (2014). Pengaruh massage effleurage terhadap nyeri persalinan pada ibu inpartu kala I fase aktif di rumah sakit ibu dan anak Sinta Bandar Lampung. Jurnal Kesehatan Holistik, 8(4),192-197. https://doi.org/ 10.33024/hjk.v8i4.271

[11] Utami, I., \& Fitriahadi, E. (2019). Buku Ajar Asuhan Persalinan \& Managemen Nyeri Persalinan. https://lppm.unisayogya.ac.id/wordpress_Ip3m/wpcontent/uploads/2020/03/BUKU-AJAR-Asuhan-Persalinan-ManagemenNyeriPersalinan_NEW_2.pdf. 